\title{
Valor de Conservação de indivíduos arbóreos e zonas de manejo em remanescente urbano de Floresta Ombrófila Mista: uma proposta metodológica
}

\author{
Valor de conservación de los individuos arbóreos y zonas de \\ gestión en remanentes urbanos de bosque templado mixto: una \\ propuesta metodológica
}

\section{Conservation value of arboreal individuals and management zones in urban remnant of Template Mixed Forest: a methodological proposal}

\author{
Carlos Hugo Rocha \\ chrocha@uepg.br \\ Universidade Estadual de Ponta Grossa, UEPG, Ponta Grossa, PR \\ Atila Cristian Santana \\ atilacristian@gmail.com \\ Universidade Estadual de Ponta Grossa, UEPG, Ponta Grossa, PR \\ Mariane Andressa Pinto Stelle Linhares \\ mari12.andressa@gmail.com \\ Universidade Estadual de Ponta Grossa, UEPG, Ponta Grossa, PR \\ Vanessa Kamila de Mello Grizafis \\ v.kamila@hotmail.com \\ Universidade Estadual de Ponta Grossa, UEPG, Ponta Grossa, PR \\ Anderson Farias \\ afarias.agro@gmail.com \\ Universidade Estadual de Ponta Grossa, UEPG, Ponta Grossa, PR \\ Rodrigo Fernando Moro \\ rodrigofmoro@yahoo.com.br \\ Consultor ambiental - HCVRN, Curitiba, PR
}

Resumo: O desmatamento de remanescentes florestais urbanos tem estimulado o debate entre perspectivas associadas ao valor do imóvel e direito de propriedade e o seu valor inerente para a conservação e função social. Para tornar objetiva a análise e valoração do componente ecológico propomos uma metodologia cientificamente embasada em ambiente SIG para auxiliar tomadores de decisão em diferentes momentos de um empreendimento imobiliário: a) no planejamento arquitetônico e de ocupação do espaço; b) no paisagismo como estratégia de conservação e compensação ambiental; c) no processo de licenciamento ambiental e definição de compensação ambiental; d) na construção e canteiro de obras; e, quando necessário, e) no processo 
de análise judicial. O modelo foi estruturado através de indicadores e índices de relevância ecológica (DAP e altura, frequência, status de ameaça regional à espécie, estágio sucessional preferencial, presença e abundância de epífitas, de frutificação e valor paisagístico) e análise da distribuição espacial destes atributos. Como referência de adequação do modelo, o resultado expresso em Zonas de Manejo após interpolação IDW foi compatível com a análise da distribuição e qualidade do remanescente florestal interpretado numa série temporal de cerca de 40 anos baseado na interpretação atual e de imagens de 1980 e 2004. Isto demonstra a viabilidade do modelo como referência objetiva da importância relativa de cada árvore, de espécies e da associação destas em zonas com relevância distinta.

Palavras-chave: área verde urbana, avaliação ambiental, geoestatística, SIG.

Resumen: La deforestación de los remanentes forestales urbanos ha estimulado el debate entre las perspectivas asociadas con el valor de la propiedad y el derecho de propiedad y su valor inherente para la conservación y la función social. Para objetivar el análisis y la valoración del componente ecológico proponemos una metodología basada científicamente en ambiente SIG para ayudar a los responsables de la toma de decisiones en diferentes momentos de un proyecto inmobiliario: a) en la planificación arquitectónica y de ocupación espacial; b) en el paisajismo como estrategia de conservación y compensación ambiental; c) en el proceso de concesión de licencias ambientales y definición de compensación ambiental; d) Construcción de obras; $Y$, cuando sea necesario, e) en el proceso de análisis judicial. El modelo se estructuró a través de indicadores e índices de relevancia ecológica (DAP y altura, frecuencia, estado de amenaza regional para la especie, etapa de sucesión preferente, presencia y abundancia de epífitas, fructificación y valor paisajístico) y análisis de distribución espacial de estos atributos. Como referencia para la adecuación del modelo, el resultado expresado en las Zonas de Gestión después de la interpolación IDW era compatible con el análisis de la distribución y la calidad del remanente forestal interpretado en una serie temporal de unos 40 años basado en la interpretación de imágenes actual y de 1980 y 2004. Esto demuestra la viabilidad del modelo como una referencia objetiva de la importancia relativa de cada árbol, especie y asociación en áreas con distinta relevancia.

Palabras clave: area verde urbana, evaluación ambiental, geoestatística, SIG.

Abstract: The deforestation of urban forest remnants has stimulated the debate among perspectives associated with the value of property and right of ownership and its inherent value for conservation and social function. To make objective the analysis and valuation of the ecological component we propose a methodology scientifically based on GIS environment to assist decision makers at different times of a real estate development: i) in architectural planning and site design; ii) in landscaping as a strategy of conservation and environmental compensation; iii) in the process of environmental licensing and definition of environmental compensation; iv) building and construction site; and, if necessary, v) in the judicial process. The model was structured through indicators and indexes of ecological relevance (DAP and height, frequency, regional threat status to the species, preferential succession stage, presence and abundance of epiphytes, fruiting, and landscape value) and analysis of the spatial distribution of these attributes. As a reference for the adequacy of the model, the result expressed in Management Zones after IDW interpolation was compatible with the analysis of the distribution and quality of the forest remnant interpreted in a time series of about 40 years based on current image interpretation and of 1980 and 2004 ones. This demonstrates the feasibility of the model as an objective reference of the relative importance of each tree, species and association in areas with distinct relevance.

Keywords: Urban green area, environmental assessment, geoestatistics, GIS. 


\section{INTRODUÇÃO}

É amplamente reconhecida a importância dos ecossistemas florestais em ambientes urbanos e seus efeitos na melhoria da qualidade ambiental, através da redução de ilhas de calor, da poluição atmosférica e sonora, aprimoramento e embelezamento da paisagem urbana e na infiltração e controle hidrológico das águas pluviais (LOBODA; DE ANGELIS, 2005; LONDE; MENDES, 2014). As florestas urbanas podem constituir mosaicos de ambientes naturais, fonte de abrigo e alimentação para aves e outros pequenos animais e sua função ecológica como elemento de conectividade na paisagem regional pode ser relevante (SANTOS; CADEMARTORI, 2010).

Melhores índices de qualidade de vida, com efeitos diretos na saúde física, mental e de longevidade de seus habitantes, estão associados a proximidade e disponibilidade de espaços de recreação e lazer em florestas e outros ambientes naturaisno contexto urbano (TAKANO; NAKAMURA; WATANABE, 2002; BARTON; PRETTY, 2010; ALCOK et al., 2014).

As cidades brasileiras carecem de áreas verdes e a expansão urbana típica promoveu alterações significativas nos remanescentesde vegetação natural (GRISE; BIOINDI; ARAKI, 2016; CAMPOS; CASTRO, 2017). Assim, solicitações para desmatamento de remanescentes florestais urbanos com significância ambiental tem estimulado o debate sobre a importância de pequenas áreas para a conservação de elementos da natureza, associada a função social da propriedade e perspectiva de bem comum e o valor do imóvel, como referência do direito à propriedade privada.

Entre o debate acadêmico e as disputas jurídicas emergentes, algumas tornam-se referência em função das particularidades ecológicas, paisagísticas e legais envolvidas, bem como dos interesses econômicos e políticos associados ao processo de tomada de decisão (BARROSO, 2007; GAIO, 2014; SELL, 2015; OLIVEIRA; OLIVEIRA, 2016; LENGLER, 2017). A disputa ambiental emergente tende a ser importante como exercício da cidadania em busca da conservação da natureza, frente a ações de caráter econômico e interesse particular e cada situação particular merece análise parcimoniosa.

Muitas vezes, no entanto, a disputa é estimulada para atender interesses particulares, sem relação direta com o valor de conservação em questão. Nesses casos, contamina-se o processo com elementos de baixa relevância ecológica e o próprio processo de tomada de decisão. Como abordado por Robertson e Hull (2001), muitas vezes a tomada de decisões revela muitas partes interessadas competindo para avançar uma agenda inerentemente política e vergonhosamente não científica - alguns valores seriam mantidos e exaltados, outros omitidos e ignorados, enquanto outros permaneceriam implícitos e despercebidos. Assim a disputa ambiental ocorre com frequência e a análise do mérito, via de regra, acontece via judicial.

Para tornar pragmática a análise do componente ecológico do processo legal, critérios cientificamente embasados podem contribuir para definição da importância de elementos arbóreos, riqueza de espécies e sua distribuição em área específica. Rosário (2010) testou parâmetros fitossociológicos usuais, como densidade, frequência, riqueza específica e uniformidade em busca de caracterização mais precisa de estágios sucessionais como 
referência à legislação, concluindo serem estes parâmetros insuficientes para adequação dos parâmetros legais à realidade ambiental.

De modo a contribuir no diálogo acadêmico e entre visões distintas e auxiliar tomadores de decisão nas disputas "conservação x desmatamento", promoveu-se este estudo de caso em um pequeno fragmento florestal como uma proposta metodológica para levantar indicadores de relevância ecológica e determinar o valor de conservação dos indivíduos arbóreos, bem como subsidiar a definição de zonas de manejo.

\section{MATERIAL E MÉTODOS}

\section{Localização e Contexto do Estudo}

A área de estudo, Chácara Eleutério, está próxima à região central de Ponta Grossa (Fig. 1), num contexto de elevada taxa de ocupação do solo e de urbanização de longa data. Trata-se de fragmento de Floresta Ombrófila Mista, formação fitogeográfica associada ao Bioma Mata Atlântica, com aproximadamente $5.000 \mathrm{~m}^{2}$, remanescente de cobertura florestal mais ampla que se conectava através de fundos de vales e encostas associadas ao sistema hidrográfico da bacia do arroio Olarias. Este fragmento florestal é constituído por indivíduos remanescentes de diferentes estágios, fruto de desmatamentos e corte seletivo pretérito. Via de regra, remanescentes florestais em áreas urbanas, não incluídos em parques ou outras áreas protegidas, encontram-se descaracterizados em relação ao padrão fitofisionômico e fitossociológico típico, como produto da conjunção de fatores que promovem sua degradação, como a poluição atmosférica, corte seletivo, desmatamento, remoção da cobertura herbácea, exposição e compactação do solo e descarte de resíduos de múltiplas origens.

\section{Inventário Florestal}

Esta área foi objeto de levantamento detalhado para inventário florestal executado para compor um EIV - Estudo de Impacto de Vizinhança (ARQUIPONTA, 2016) que compreendeu levantamento florístico, determinação do diâmetro na altura do peito (DAP), altura e a quantificação volumétrica da totalidade dos indivíduos encontrados na área. As árvores foram mapeadas em coordenadas UTM, com auxílio de GPS, integrado em Sistema de Informações Geográficas (SIG) para gerar mapa com a localização espacial das árvores transformadas em arquivo digital (formato shape).

Uma AER - Avaliação Ecológica Rápida (SAYRE et al., 2000), foi conduzida em julho e agosto de 2017 para verificar a exatidão dos dados do EIV, bem como um reconhecimento com drone, base para a análise espacial subsequente a partir de pontos (árvores) e atributos levantados. Para determinação das espécies, foi considerado porte, conformação da copa, características das flores e frutos (quando presentes), conforme Lorenzi (1992, 2014) e SIDOL (on line). A indicação do estágio sucessional das espécies (bioindicadores) 
foi obtida da literatura, principalmente Maciel et al. (2003), Castela e Britez (2004) e Inoue, Roderjan e Kunioshi (1984).

Em campo foram re-amostrados 24 indivíduos, incluindo as dez árvores com o maior DAP e outras 14 escolhidas aleatoriamente por caminhamento, conforme Filgueiras et al. (1994). As espécies selecionadas foram checadas ao nível de espécie e dados de DAP re-coletados com auxílio de trena e fita métrica, além da coleta de dados para os índices de relevância ecológica descritos a seguir.

Figura 1: Localização e perímetro da área em estudo e contexto local em imagem Google Earth, de 24/06/2017.

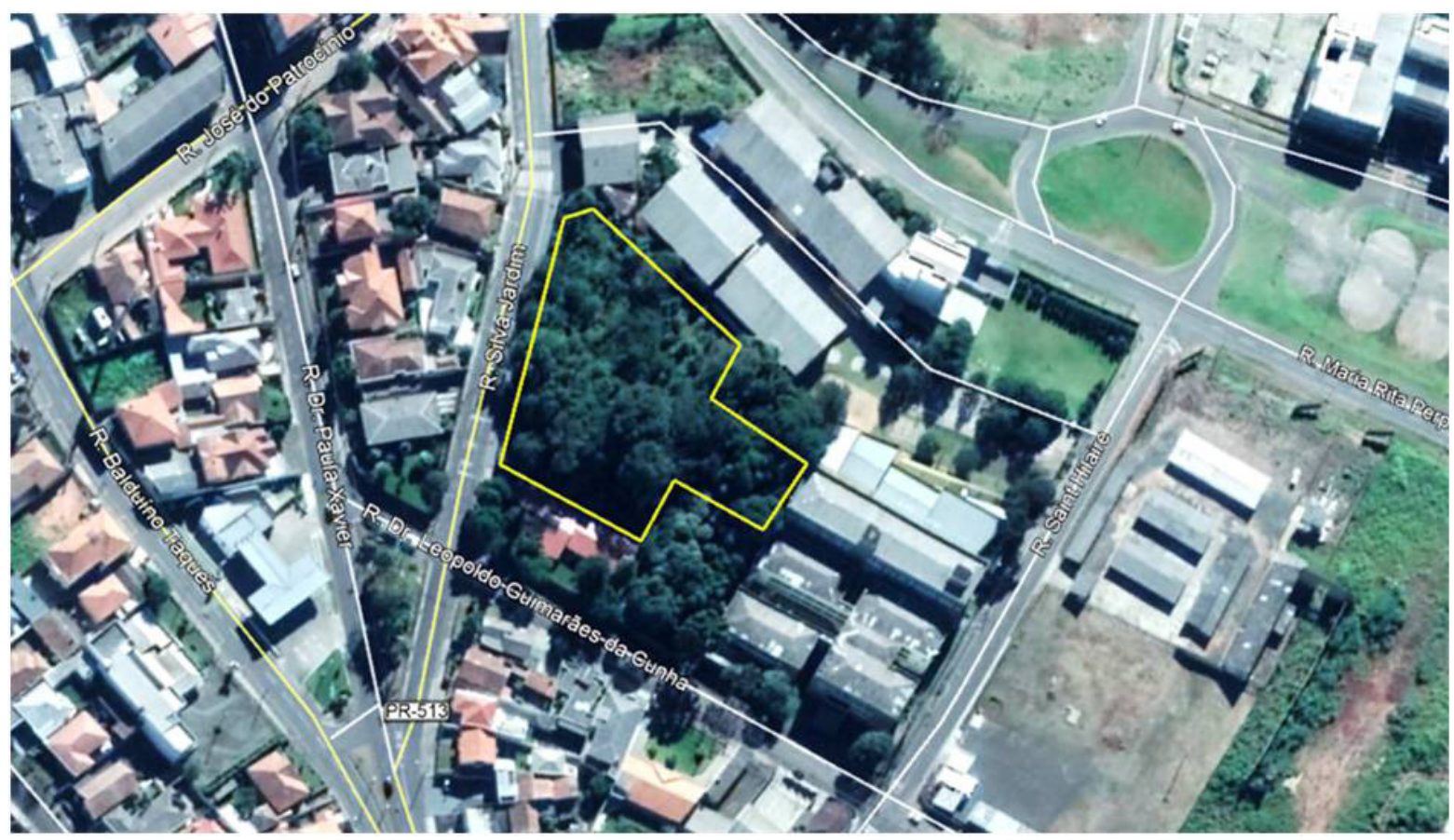

Fonte: os autores.

\section{Indicadores de Relevância Ecológica e Valor de Conservação}

Prioridades para conservação foram definidas a partir da seleção de indicadores que forneçam informações tangíveis sobre a importância do componente arbóreo e a relevância ecológica do fragmento florestal remanescente. Para compor o Valor de Conservação (VC) foram selecionados como indicadores de relevância ecológica sete índices:

a. Índices de Diâmetro do Tronco na Altura do Peito (I-DAP) e Altura (I-h), determinados a partir da relação entre a Mediana DAP/DAP individual e Mediana $h / h$ individual, de modo a obter intervalo contínuo entre os índices.

b. Índice de Valor Ecológico (I-VE) baseado nas categorias de risco de extinção regional conforme o Livro Vermelho da Flora do Brasil (MARTINELLI; MORAES, 2013). Os índices foram definidos como (CR) Criticamente em perigo: $\mathrm{I}-\mathrm{VE}=10$; (EN) Em perigo: $\mathrm{I}-\mathrm{VE}=$ 5; (VU) Vulnerável: I-VE = 3; Em declínio: I-VE = 1 . 
c. Índice de Sucessão Ecológica (I-SE), que confere pesos à posição ocupada pela espécie no estágio de regeneração florestal preferencial, segundo dados de literatura, definido como: (P) Pioneiras - I-SE = 0; (S) Secundárias - I-SE = 1; (C) Clímax - I-SE = 2.

d. Índice de Presença, Abundância e Diversidade de Plantas Epífitas (I-E)- plantas que contribuem para a diversificação de nichos e micro-hábitats, aumentando consideravelmente o espaço físico e o alimento disponível, além de servirem como refúgio reprodutivo a muitas espécies. Foi estabelecido a partir da avaliação qualitativa relativa, através de caminhamento, correspondente a: Ausência - I-E = 0; Presença pouco relevante - I-E = 1; Presença relevante - I-E = 2; Presença muito relevante- I-E $=3$.

e. Índice de Frutificação (I-Frut) - reconhecendo a importância da produção de frutos na alimentação de espécies frugívoras e seu papel ecológico como dispersores de sementes, por aves migratórias ou de nidificação local, segundo informação disponível na literatura. Foi estabelecido a partir da avaliação qualitativa relativa, através de caminhamento, definida como: Frutificação pouco abundante: I-Frut = 0; Frutificação abundante: I-Frut $=1$; Frutificação muito abundante: I-Frut $=2$.

f. Índice de Valor Paisagístico (I-VP) - a partir da avaliação de espécies nativas com elevado potencial ornamental e utilizadas como componentes em trabalhos de paisagismo urbano, parque e jardins (porte e proporção, textura de troncos e folhagem, padrão de galhos e de copa, florescimento e fragrâncias, entre outros). Foram avaliadas as dez árvores com maior DAP e outras 14 com potencial paisagístico, selecionadas através de caminhada sistemática na área. As espécies presentes na área e destacadas na literatura como de alto valor para paisagismo também foram incluídas. O I-VP foi definido como: Pouco relevante -I-VP = 0; Relevante - I-VP = 1; Alta Relevância - I-VP = 2; Muito Alta Relevância - I-VP $=3$.

g. Índice de Frequência Relativa (I-Freq), usando o inverso da frequência relativa como indicador de raridade da espécie na população inventariada, ou seja, foram valorizadas as espécies com menor ocorrência na população.

\section{Valor de Conservação (I-VC)}

Para definir a prioridades de conservação entre os indivíduos arbóreosna área, os índices dos indicadores de relevância ecológica de cada indivíduo arbóreo (i) foram computados em SIG, de modo a constituir o índice $\mathrm{VC}\left({ }_{\mathrm{i}}\right)$, de acordo com a equação:

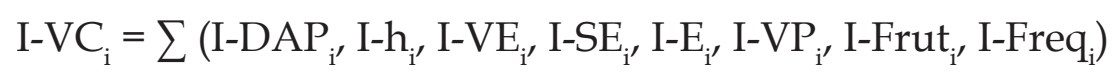

Os índices VC de cada indivíduo (VCi) foram agrupados em 5 classes de prioridade de classificação através de algoritmo Quebra Natural (JENKS, 1977). Este método busca minimizar a variância intra-classes e maximizar a variância inter-classes e sua base matemática gera intervalos de valores de acordo com a tendência natural de agrupamento e apresenta adaptabilidade em seu uso e elevada acurácia para a divisão entre classes (CHEN et al., 2013; RIBEIRO; MARTINS; JOHNSSON., 2016). 


\section{Zonas de Manejo}

Foram elaborados mapas com o zonemaneto de manejo para evidenciar setores com maior potencial para a conservação em função da configuração espacial e proximidade entre indivíduos arbóreos com maior I-VC. A definição de zonas proporciona uma perspectiva ecológica de toda a área e, assim, subsidiar em diferentes momentos o processo de tomada de decisão sobre a viabilidade (ou não) da ocupação do espaço. Também proporciona diferentes configurações entre elementos arquitetônicos para o planejamento de ocupação de modo a viabilizar a conservação de elementos arbóreos mais significativos.

O zoneamento foi produzido a partir da análise espacial em ambiente SIG, elaborada com auxílio do interpolador geoestatístico Inverso da Distância Ponderada (Inverse Distance Weighting - IDW) entre os I-VC. Este modelo estatístico fundamenta-se na dependência espacial, assumindo que valores mais próximos são mais relacionados, atribuindo maior peso para observações mais próximas do que para as mais distantes. Pode ser ajustado para incluir uma potência para as distâncias entre os pontos de modo a atribuir pesos diferentes aos vizinhos mais próximos no valor a ser estimado para os setores sem observação. Foram empregados 12 metros como raio de distância máxima para selecionar pontos de estimativa do valor interpolado; 12 como o número de vizinhos utilizados para estimar o valor interpolado, na potência 3. Nesse caso valorizou-se a proximidade entre as árvores em função da influência recíproca do sistema radicular, bem como os setores com maior concentração de indivíduos com I-VC elevado.

\section{Análise do Modelo de Valor de Conservação}

Os resultados espaciais obtidos para os I-VC e as Zonas de Manejo foram superpostos em ambiente SIG à fotografias aéreas georreferenciadas de 1980 (escala 1:25.000) e imagem do satélite Ikonos de 2004 (resolução espacial 4 m) para verificar a validade do modelo desenvolvido, comparando estes resultados às informações obtidas nas imagens através de técnicas de fotointerpretação visual (AVERY; BERLIN, 1993).

\section{RESULTADOS E DISCUSSÃO}

\section{Contexto local e indicadores de Relevância Ecológica}

No inventário florestal de referência foi registrada a presença de 105 indivíduos arbóreos, incluindo 17 que apresentaram 2, 3 ou 4 fustes, totalizando 129 fustes individuais considerados neste estudo. Foram determinadas 31 espécies arbóreas de 16 famílias botânicas, sendo Lauraceae e Fabaceae as famílias mais representativas com 7 e 4 espécies, respectivamente; Meliaceae com 24 indivíduos e Fabaceae com 23 obtiveram a maior abundância de indivíduos (Quadro 1). Na AER foram observadas 28 espécies arbóreas 
de 15 famílias botânicas; uma vez que o estrato arbustivo não foi considerado, Psychotria vellosiana (Jasmim) não foi contabilizada.

São resultados compatíveis com a diversidade de Floresta Ombrófila Mista típica, mas notável considerando o histórico de ocupação urbana deste fragmento. Destaca-se ausência de Araucariaceae (típica do extrato superior) e Myrtaceae (típicas do sub-bosque), ambas comuns nos ambientes nativos típicos, o que reforça a presença de antropismo.

As fotografias aéreas de 1980 (Fig. 2) e 2002 (Fig. 3) revelam a progressiva ocupação de um fragmento florestal mais amplo que o atual e a existência de clareiras indicadoras de ocupação anterior por moradia, já ausente no período analisado. Este bosque é provável remanescente de maciço florestal que dominava esta porção da paisagem quando o núcleo urbano se expande nesta direção após a implantação da malha ferroviária em finais do século XIX.

Figura 2: Limites da área de estudo, uso do entorno e distribuição espacial de indivíduos arbóreos em fotografia aérea de 1980.

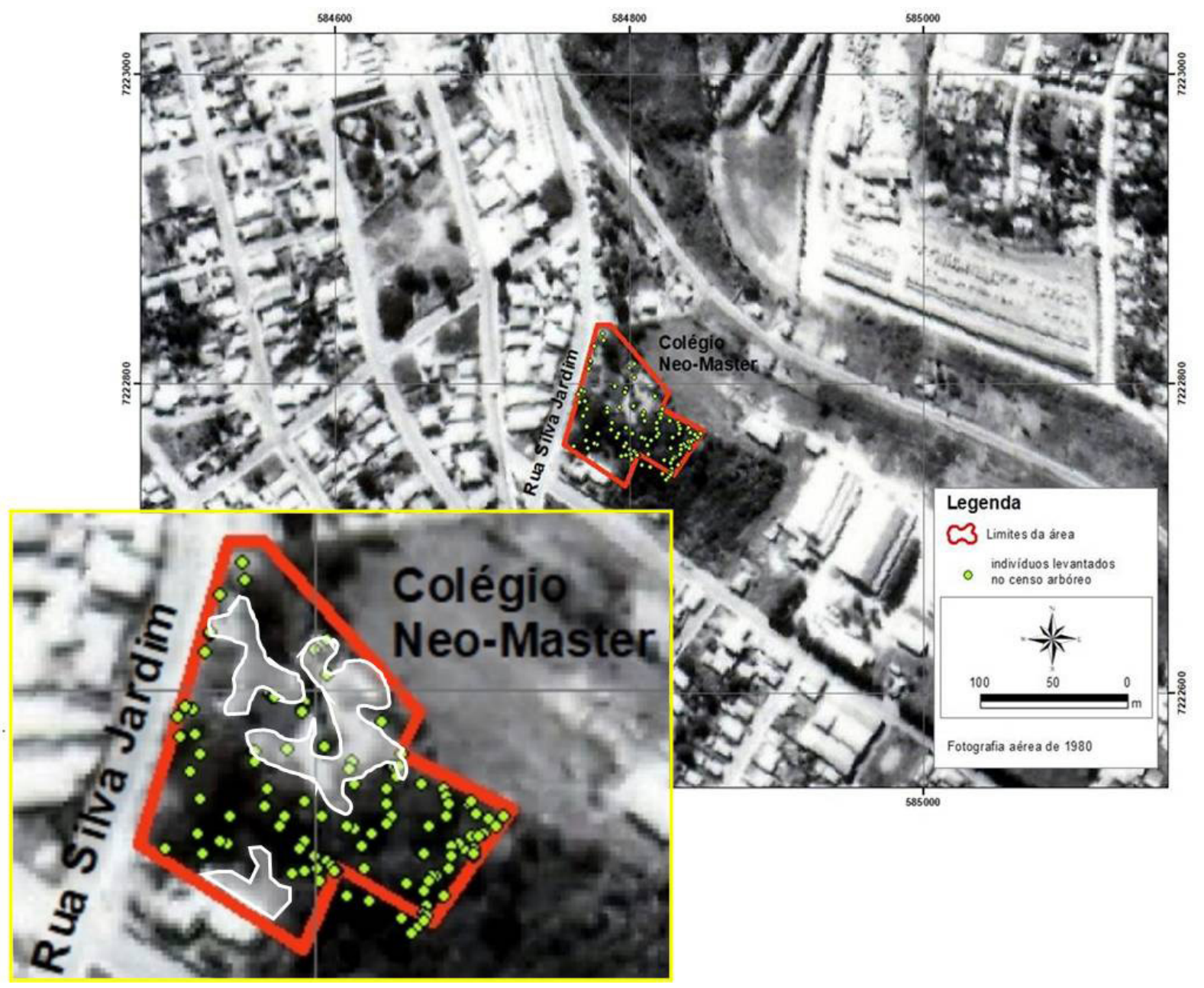

Fonte: os autores. 
Figura 3: Limites da área de estudo, distribuição espacial dos indivíduos arbóreos levantados e urbanização do entorno em fotografia aérea de 2002.

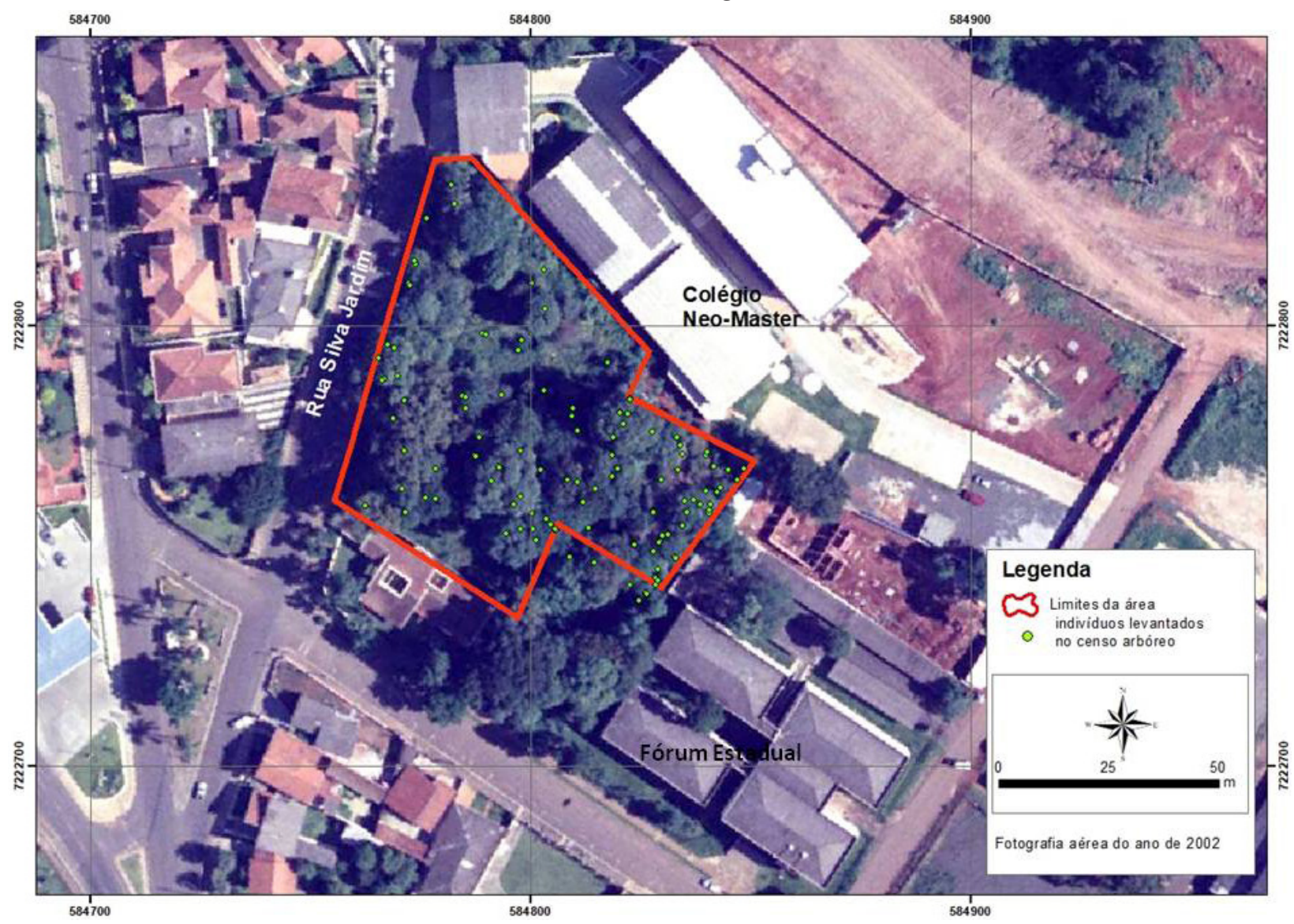

Fonte: os autores.

A Figura 4 apresenta a distribuição espacial dos indivíduos arbóreos e de classes de diâmetro (DAP) na área. Há um elevado número de indivíduos associados às classes de menor diâmetro (mediana inferior a $28,12 \mathrm{~cm}$ ), o que denota um processo de regeneração natural. Indivíduos com presença muito antiga são representados por 19 fustes com diâmetro superior a $60 \mathrm{~cm}$ (e cinco maiores que $90 \mathrm{~cm}$ ), todos situados na porção meridional da área. 
Figura 4: Distribuição espacial das espécies arbóreas e suas classes de DAP. Os números no mapa correspondem a identificação dos indivíduos na tabela de atributos (resumida no Quadro 1).

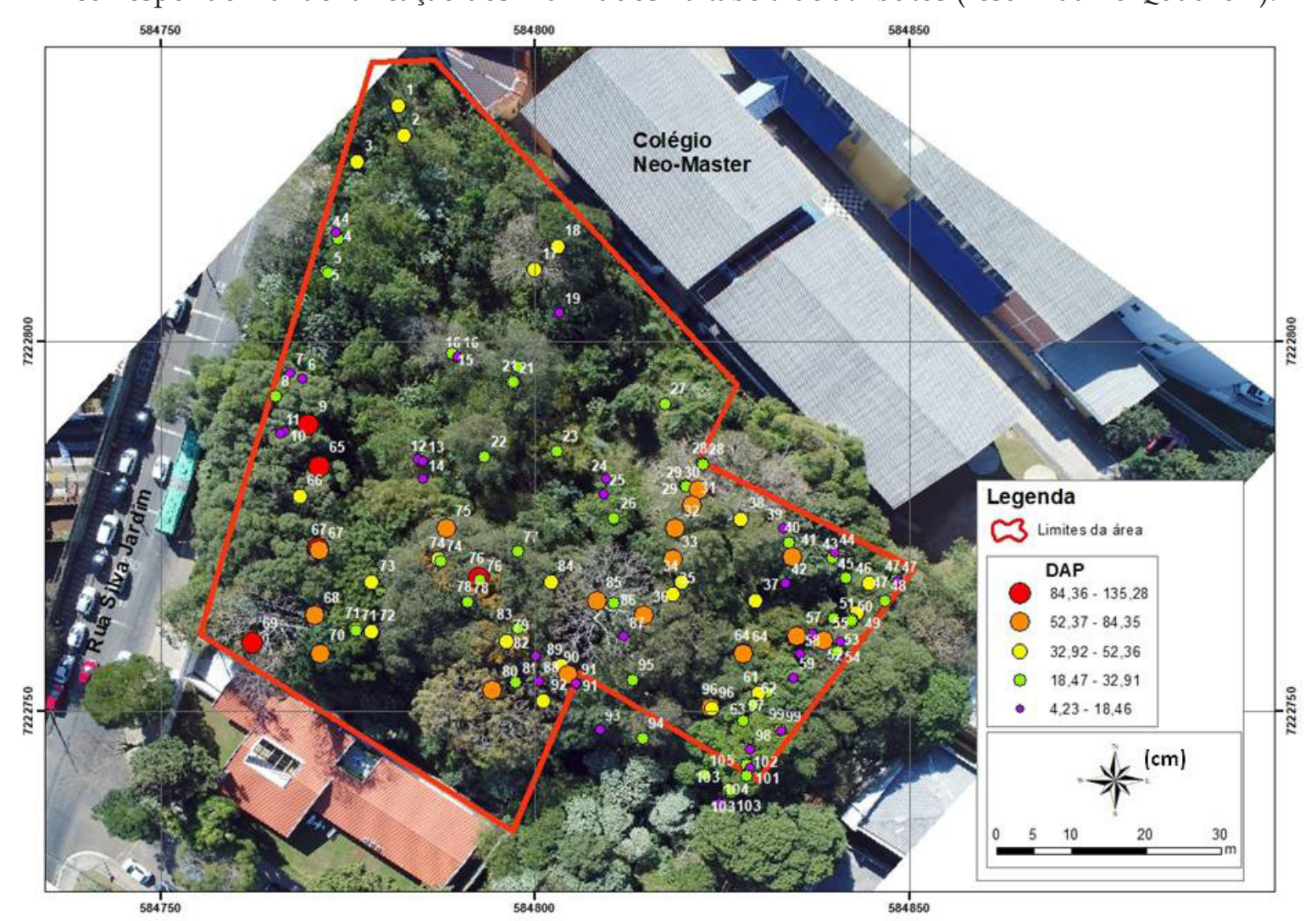

Fonte: os autores.

Quadro 1: Resumo das espécies e seus parâmetros de conservação conforme tabela de atributos dos 105 indivíduos levantados.

\begin{tabular}{|c|c|c|c|c|c|}
\hline Família & Nome científico & Nome popular & $\begin{array}{c}\text { Numero de } \\
\text { indivíduos }\end{array}$ & $\begin{array}{c}\text { Estágio } \\
\text { Sucessional }\end{array}$ & $\begin{array}{c}\text { Categoria de } \\
\text { Risco }\end{array}$ \\
\hline Anacardiaceae & Lithraea molleoides & Aroeira-branca & 2 & Secundária & \\
\hline Annonaceae & Xylopia brasiliensis & Pindaíba & 1 & Secundária & Em declínio \\
\hline Apocynaceae & Rauvolfia sellowii & Casca-d'-anta & 2 & Secundária & - \\
\hline Arecaceae & Syagrus romanzoffiana & Jerivá & 3 & Primária & - \\
\hline Cannabaceae & Trema micrantha & Pau-pólvora & 4 & Primária & - \\
\hline Caricaceae & Vasconcellea quercifolia & Mamoeiro-do-campo & 2 & Primária & - \\
\hline Euphorbiaceae & Sapium glandulosum & Leiteiro & 2 & Primária & - \\
\hline \multirow{5}{*}{ Fabaceae } & Bauhinia fortificata & Pata-de-vaca & 11 & Secundária & - \\
\cline { 2 - 6 } & Machaerium nyctitans & Jacarandá-bico-de-pato & 4 & Primária & - \\
\cline { 2 - 6 } & Machaerium stipitatum & Sapuva & 4 & Secundária & - \\
\cline { 2 - 6 } & Senna macranthera & Pau-fava & 4 & Secundária & - \\
\hline \multirow{5}{*}{ Lauraceae } & Nectandra lanceolata & Canela-amarela & 3 & Secundária & - \\
\cline { 2 - 6 } & Ocotea acutifolia & Canela-branca & 2 & Clímax & - \\
\cline { 2 - 6 } & Ocotea porosa & Imbuia & 2 & Clímax & Em perigo \\
\cline { 2 - 6 } & Ocotea puberula & Canela-guaiacá & 7 & Secundária & - \\
\cline { 2 - 6 } & Ocotea pulchella & Canelinha & 2 & Clímax & - \\
\cline { 2 - 6 } & Persea americana & Abacateiro & 1 & Exótica & - \\
\hline
\end{tabular}


conclusão

\begin{tabular}{|c|c|c|c|c|c|}
\hline Família & Nome científico & Nome popular & $\begin{array}{l}\text { Numero de } \\
\text { indivíduos }\end{array}$ & $\begin{array}{c}\text { Estágio } \\
\text { Sucessional }\end{array}$ & $\begin{array}{c}\text { Categoria de } \\
\text { Risco }\end{array}$ \\
\hline Malvaceae & Luehea divaricata & Açoita-cavalo & 2 & Primária & - \\
\hline \multirow{3}{*}{ Meliaceae } & Cabralea canjerana & Canjerana & 9 & Secundária & \\
\hline & Cedrela fissilis & Cedro & 14 & Clímax & Vulnerável \\
\hline & Guarea kunthiana & Figo-do-mato & 1 & Clímax & - \\
\hline Moraceae & Ficus glabra & Figueira-do-mato & 1 & Secundária & - \\
\hline Nyctaginaceae & Pisonia zapallo & Maria-faceira & 4 & Secundária & - \\
\hline \multirow{2}{*}{ Rubiaceae } & Coussarea contracta & Cinzeiro-preto & 2 & Secundária & - \\
\hline & Psychotria vellosiana & Jasmin & 2 & Clímax & - \\
\hline \multirow{2}{*}{ Rutaceae } & Citrus spp. & Limoeiro & 1 & Exótica & - \\
\hline & Zanthoxylum kleinii & Juvevê & 1 & Secundária & - \\
\hline Salicaceae & Casearia sylvestris & Café-do-mato & 1 & Secundária & - \\
\hline \multirow{7}{*}{ Solanaceae } & Solanum compressum & Fumeiro & 3 & Primária & - \\
\hline & Solanum granuloso-leprosum & Fumo-bravo & 3 & Primária & - \\
\hline & Solanum mauritianum & Fumo-bravo & 1 & Primária & - \\
\hline & Não identificada 1 & - & 1 & - & - \\
\hline & Não identificada 2 & - & 1 & - & - \\
\hline & Não identificada 3 & - & 1 & - & - \\
\hline & Não identificada 4 & - & 1 & - & - \\
\hline
\end{tabular}

Fonte: os autores, mod. de Arquiponta, 2016.

Na Figura 5 verifica-se a distribuição dos indivíduos classificados por espécie e status de ameaça (Valor Ecológico I-VE). Ocotea porosa, com dois indivíduos, é considera Em Perigo de Extinção e, portanto, sua conservação merece destaque especial no contexto desta análise, assim como 14 indivíduos de Cedrela fissilis, incluída na categoria Vulnerável e um indivíduo de Xylopia brasiliensis, considerada Em Declínio. 
Figura 5: Distribuição espacial do I-VE das espécies arbóreas levantadas. Os números no mapa correspondem a identificação dos indivíduos na tabela de atributos.

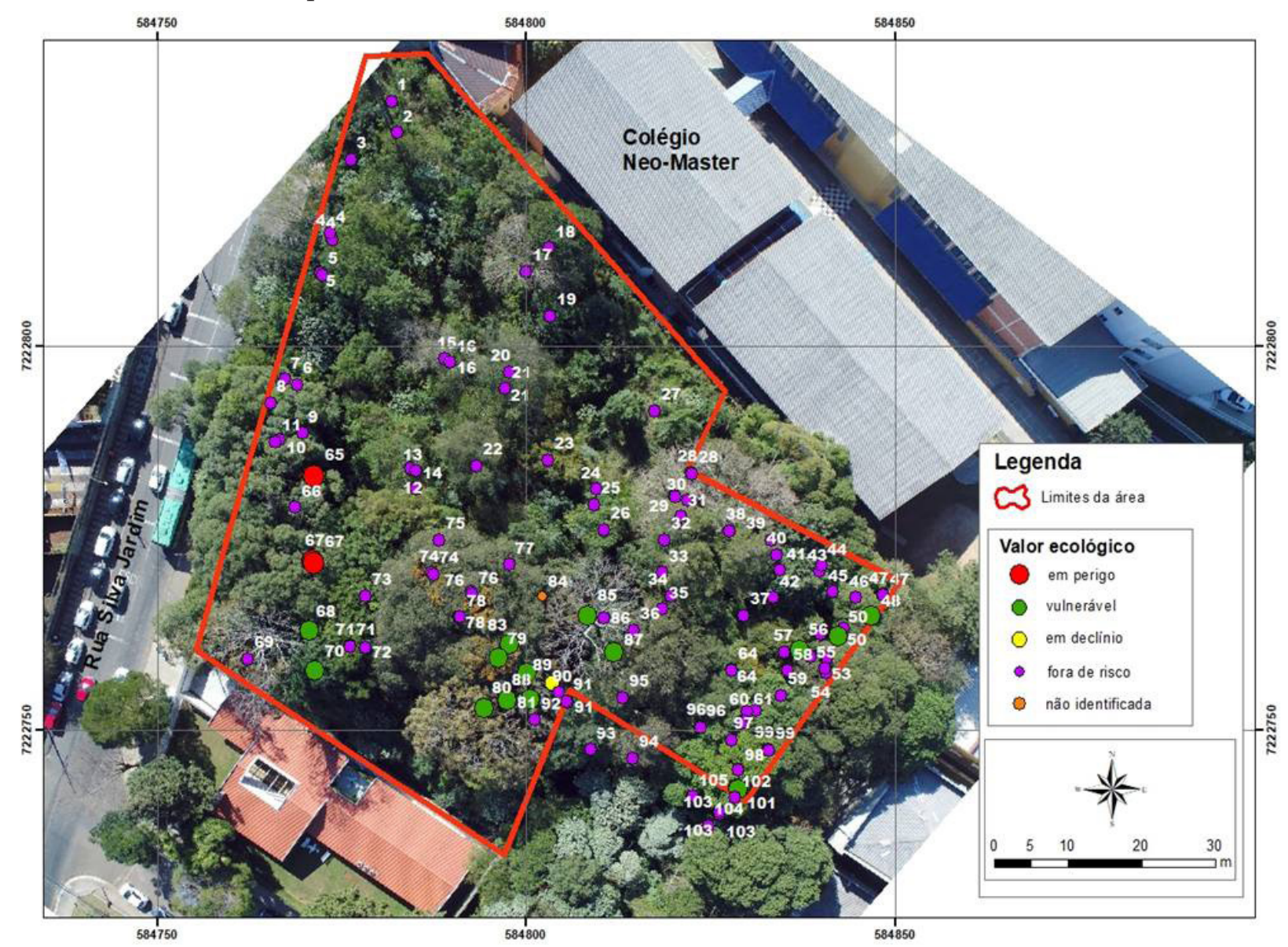

Fonte: os autores.

Em relação ao estágio de Sucessão Ecológica I-SE (Fig. 6), nove espécies são típicas de floresta primária, 14 de florestas secundárias e seis de formação clímax, além de duas exóticas. As espécies climácicas estão distribuídas principalmente na porção meridional da área em estudo, compreendendo 31 indivíduos: Ocotea porosa, Ocotea pulchella, Ocotea acutifolia, Guarea kunthiana, Psychotria vellosiana e Rauvolfia sellowii. 
Figura 6: Distribuição espacial do I-SE das espécies arbóreas levantadas. Os números no mapa correspondem a identificação dos indivíduos na tabela de atributos.

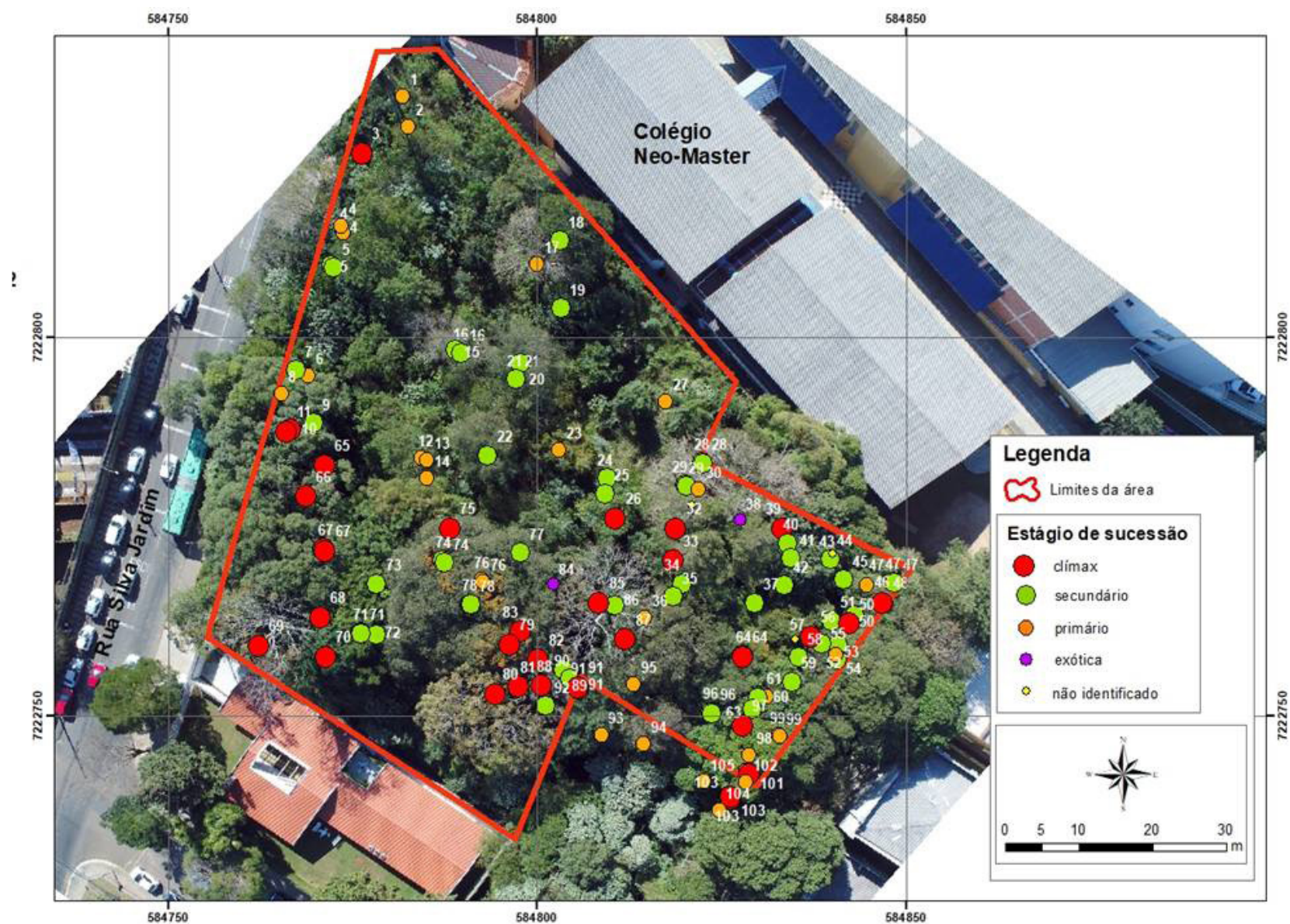

Fonte: os autores.

Através da distribuição espacial do índice de Epífitas (I-E), apresentada na Figura 7, e o índice de Valor Paisagístico I-VP (Fig. 8) percebe-se que os maiores índices estão distribuídos na porção meridional da área, bem como a distribuição espacial do índice de Frutificação I-Frut, indicador do potencial de produção de alimentos para a avifauna ao longo do ano, e do índice de Frequência I-Freq, indicador da raridade da espécie na área. 
Figura 7: Distribuição espacial do I-E das espécies arbóreas levantadas. Os números no mapa correspondem a identificação dos indivíduos na tabela de atributos.

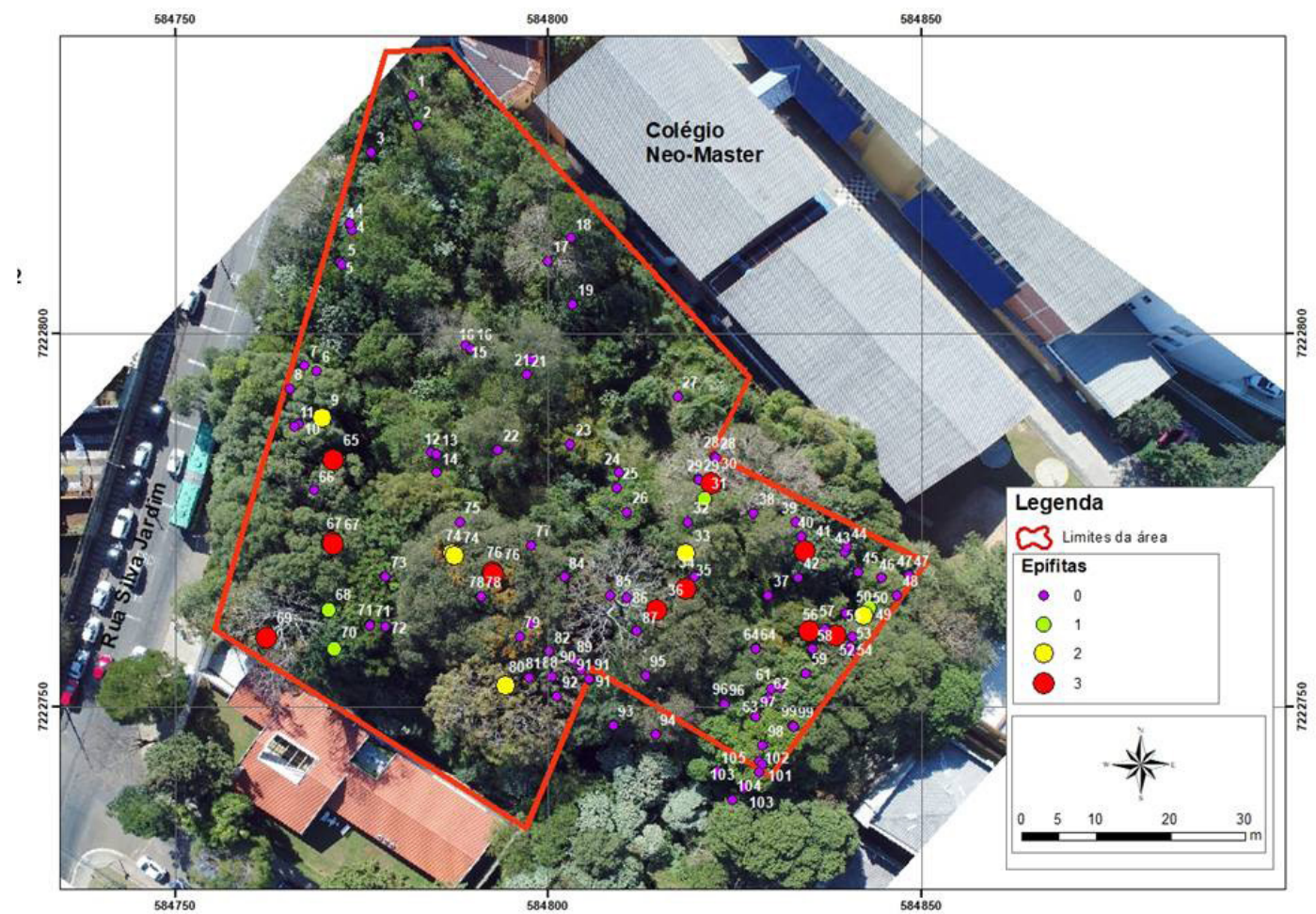

Fonte: os autores.

Figura 8: Distribuição espacial do I-VP das espécies arbóreas levantadas. Os números no mapa correspondem a identificação dos indivíduos na tabela de atributos.

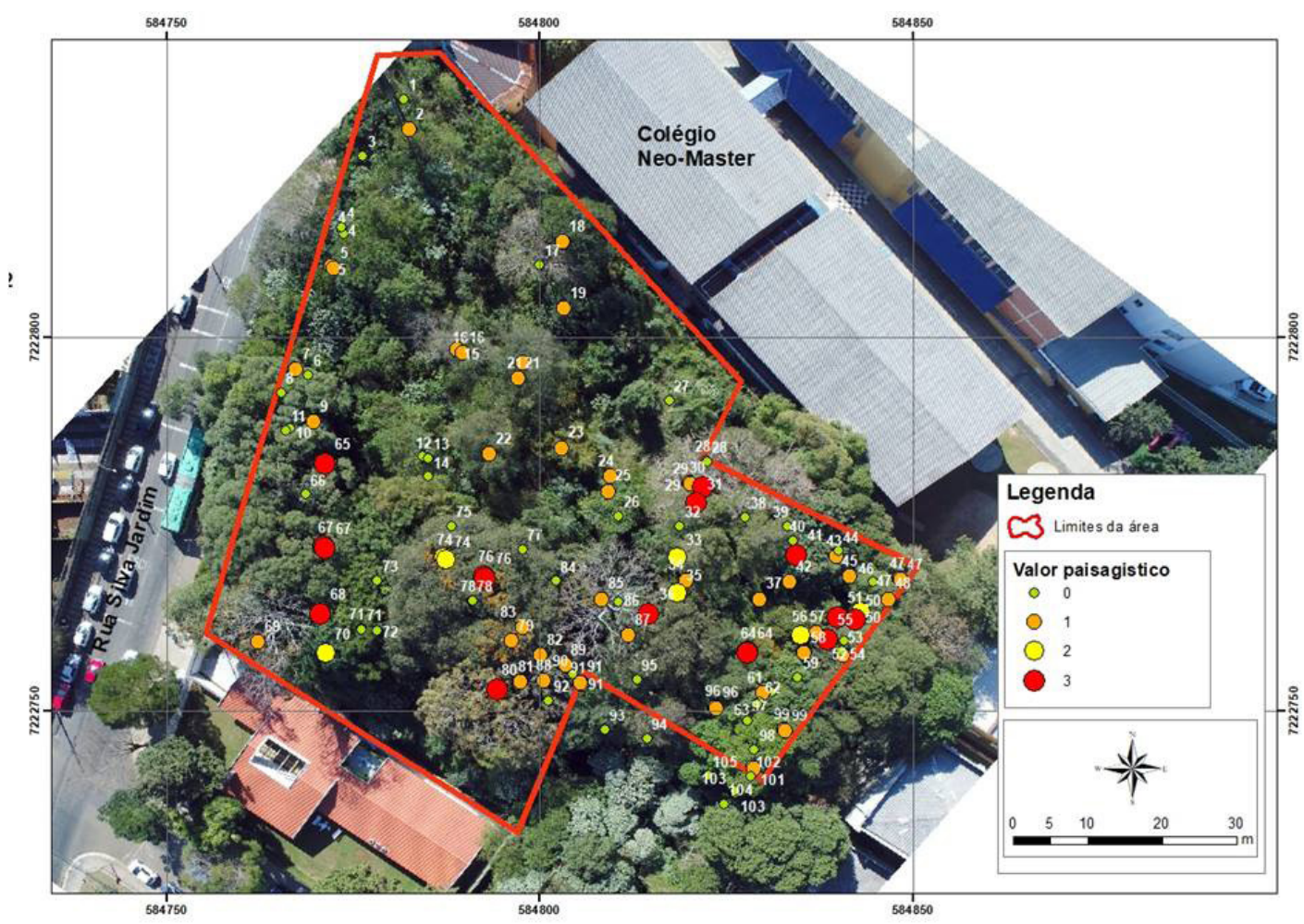

Fonte: os autores. 


\section{Valor de Conservação}

A partir do somatório dos índices de Indicadores de Relevância Ecológica determinou-se o I-VC dos indivíduos arbóreos. A Figura 9 apresenta a distribuição espacial dos indivíduos agrupados em classes de VC, e a Figura 10 a distribuição das classes. Os índices variaram, do mais baixo - 0,67 (Citrus spp, espécie exótica, n. 84) até 19,33 (Ocotea porosa - espécie em risco de extinção, n. 65), tendo como média 6,15 e mediana, 4,86. Como resultante das análises anteriores, os maiores I-VC estão situados na porção meridional da área de estudo.

Figura 9: Distribuição espacial e I-VC das espécies arbóreas levantadas.. Os números no mapa correspondem aos indivíduos na tabela de atributos.

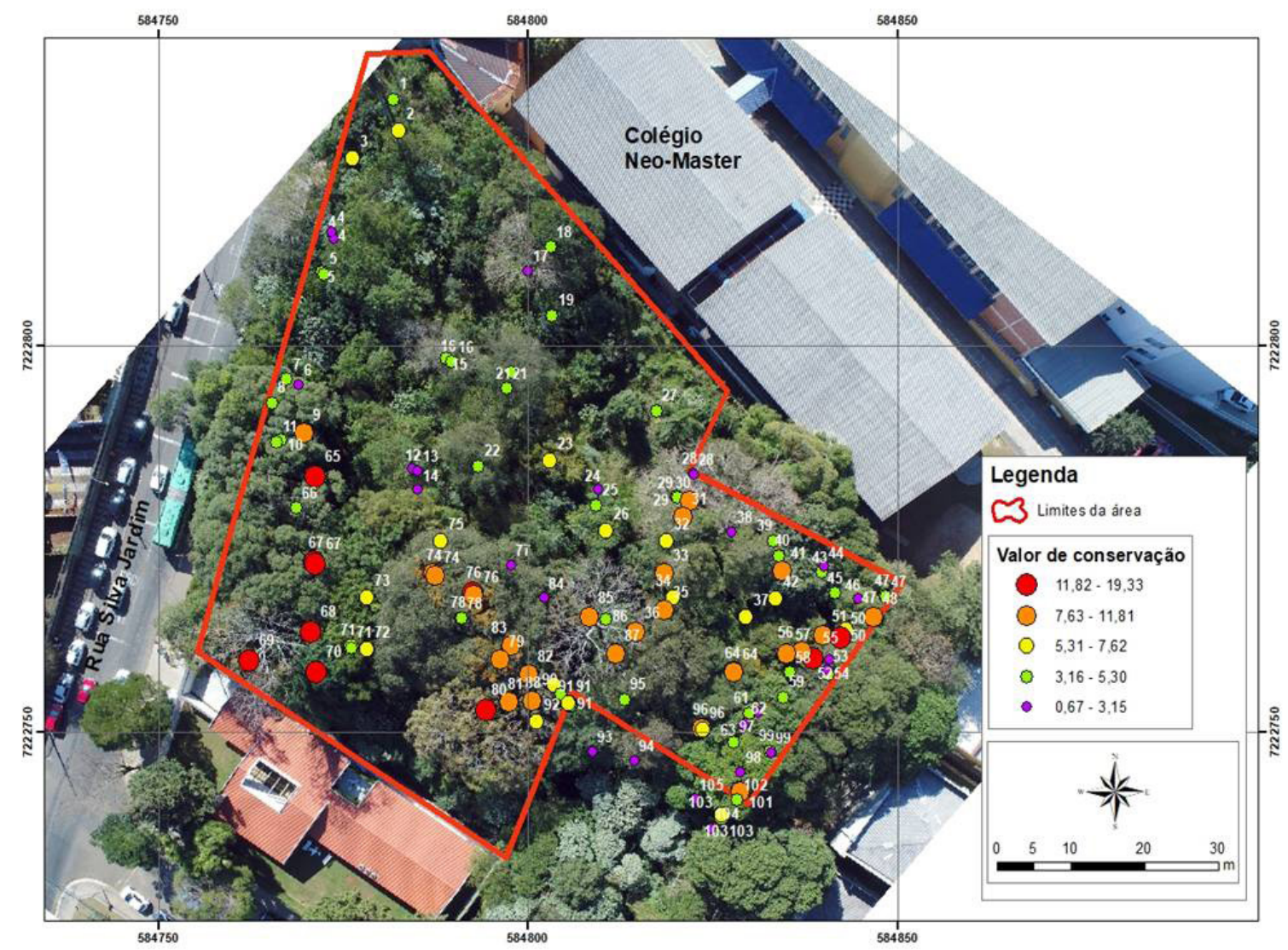

Fonte: os autores.

As espécies de maior relevância ecológica, com os maiores I-VC, foram Ocotea porosa, com dois indivíduos e I-VC médio de 18,90; Cedrela fissilis, com 14 indivíduos e I-VC de 8,17 (indivíduo jovem, com menor I-DAP e I-h e ausência de outros atributos notáveis) a 15,38 (indivíduo maduro, com elevado I-DAP e I-h, presença abundante de epífitas e relevante valor paisagístico); Rauvolfia sellowii, com dois indivíduos e I-VC de 10,95 e Luehea divaricata, com dois indivíduos e I-VC de 10,71. 
Figura 10: Distribuição de Classes de I-VC das espécies arbóreas levantadas.

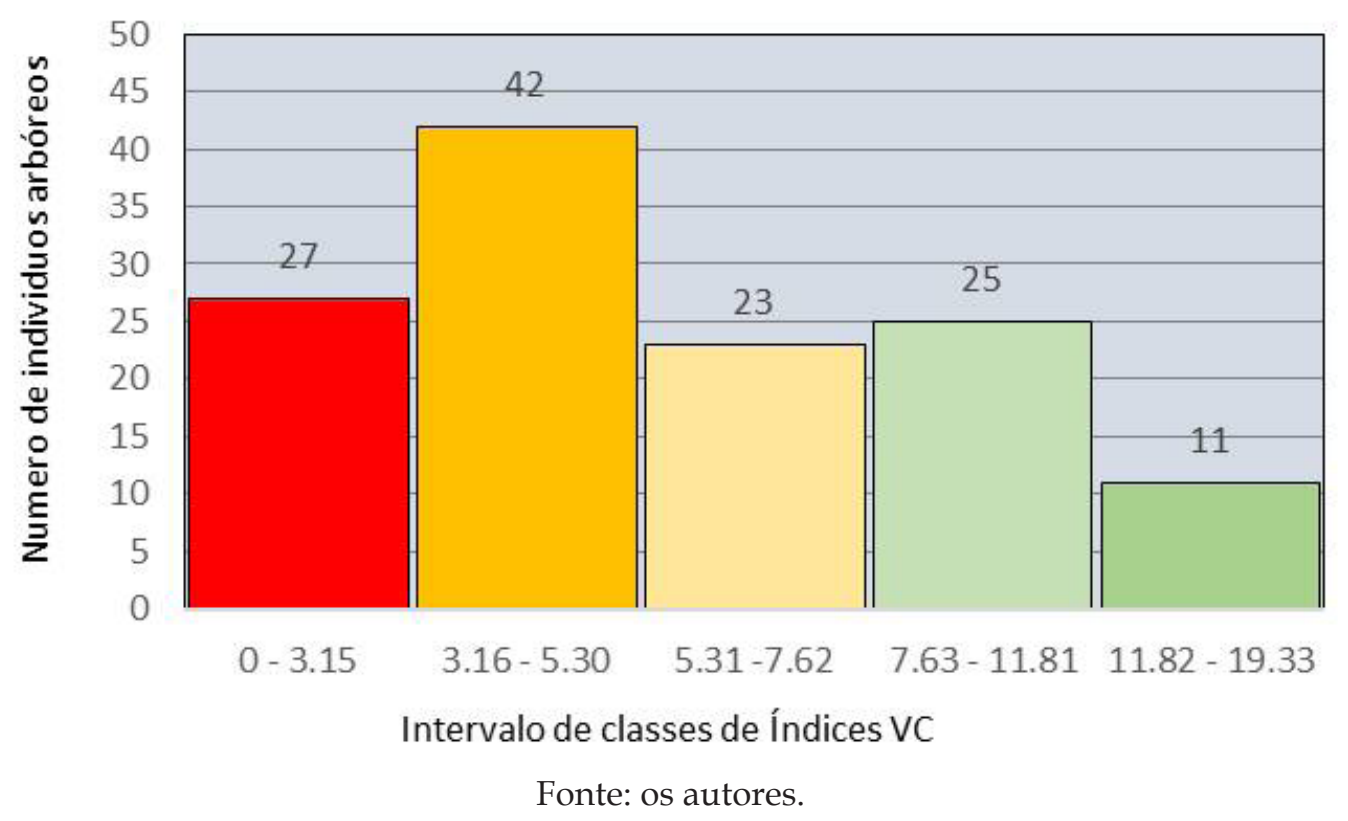

\section{Zonas de Manejo}

Através do interpolador IDW se definiram Zonas de Manejo que representam intervalos de classes de I-VC, considerando os 12 indivíduos mais próximos, ponderado pela distância relativa de cada árvore em seu contexto de inserção, de 12 m, a distância máxima considerada.

As Zonas de Manejo podem ser interpretadas como áreas de influência recíproca entre indivíduos arbóreos com maiores ou menores I-VC, e correspondem a zona de interpenetração entre raízes e copas destas árvores. São, assim, indicadores da viabilidade de ocupação dos solos com diferentes estruturas construtivas nas zonas com menores índices e por paisagismo conservacionista nas demais.

Na área em estudo, as zonas de maior valor de conservação, com maiores índices (> 10.39), representam as áreas e indivíduos arbóreos mais relevantes cuja conservação deve ser priorizada em um projeto de ocupação do imóvel. Estão distribuídas essencialmente na porção meridional e correspondem as áreas com cobertura mais florestal mais expressiva, com indivíduos com maior DAP e altura, maior presença e diversidade de epífitas, valor paisagístico mais relevante, típicos de estágios mais avançados de sucessão ecológica e inclui espécies em risco de extinção. Da mesma forma ficaram evidentes zonas com menor valor de conservação, com menores índices $(<7.25)$, para as quais pode ser direcionado o planejamento arquitetônico para ocupação do espaço potencialmente construtivo, distribuídas na porção setentrional que correspondem à áreas historicamene antropizadas (Fig. 11). A zona intermediária (entre 7.25 - 10.38), representa setores que merecem atenção especial no planejamento da ocupação e no processo construtivo, demandando análise particular de cada indivíduo arbóreo para evitar cortes desnecessários de indivíduos ou espécies significativas, de modo a valorizar o potencial ecológico e manter benefícios ambientais do remanescente. 
Figura 11: Distribuição espacial de I-VC das espécies arbóreas levantadas e Zonas de Manejo na área de estudo.

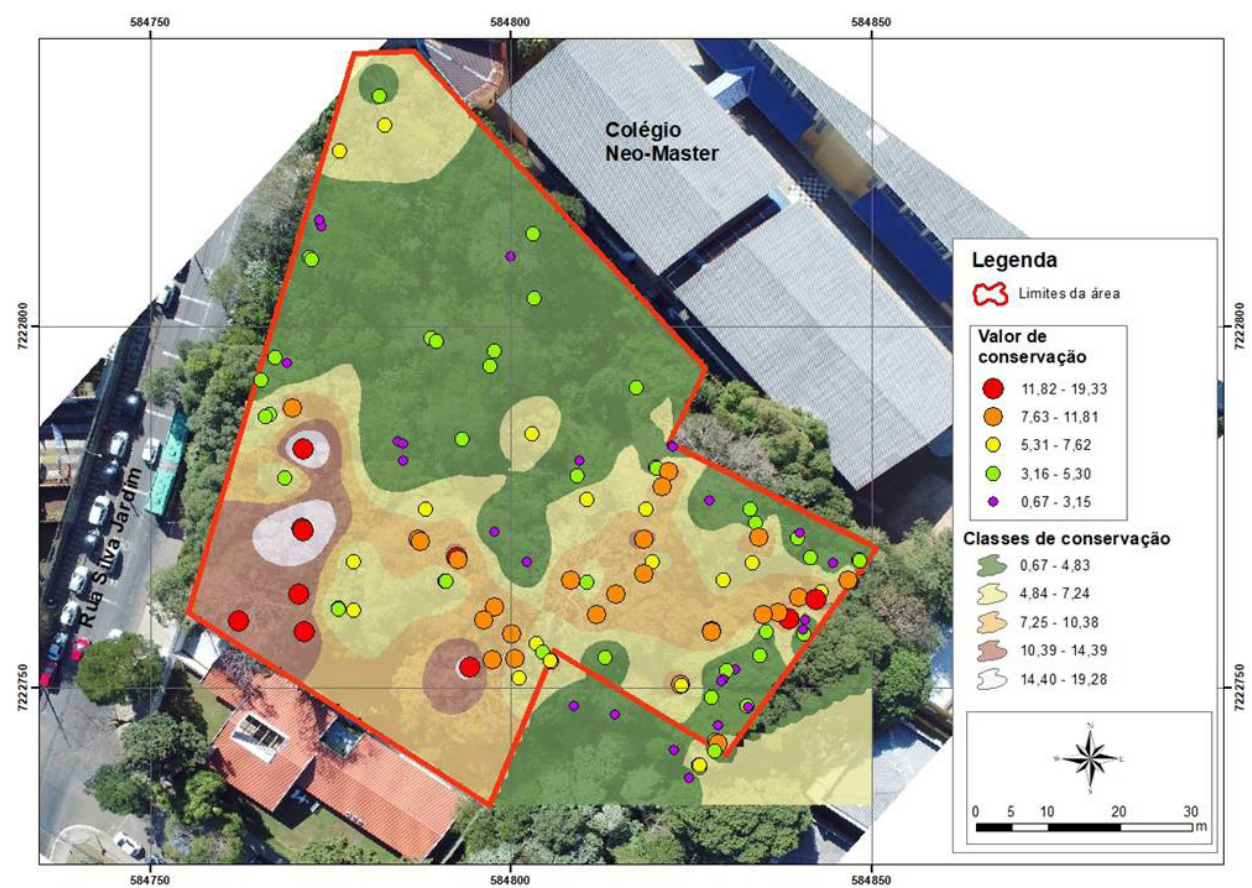

Fonte: os autores.

A sobreposição do mapa de Valor de Conservação com a fotografia aérea de 1980 (Fig. 12) e imagem de 2004 (Fig. 13) ilustram o potencial do modelo adotado, pois são coincidentes com as Zonas de Manejo com valores inferiores $(<7,25)$ e intermediário $(7,25-10,38)$.

Figura 12: Sobreposição das Classes de Conservação determinadas com a tomada de dados atual sobre fotografia aérea de 1980.

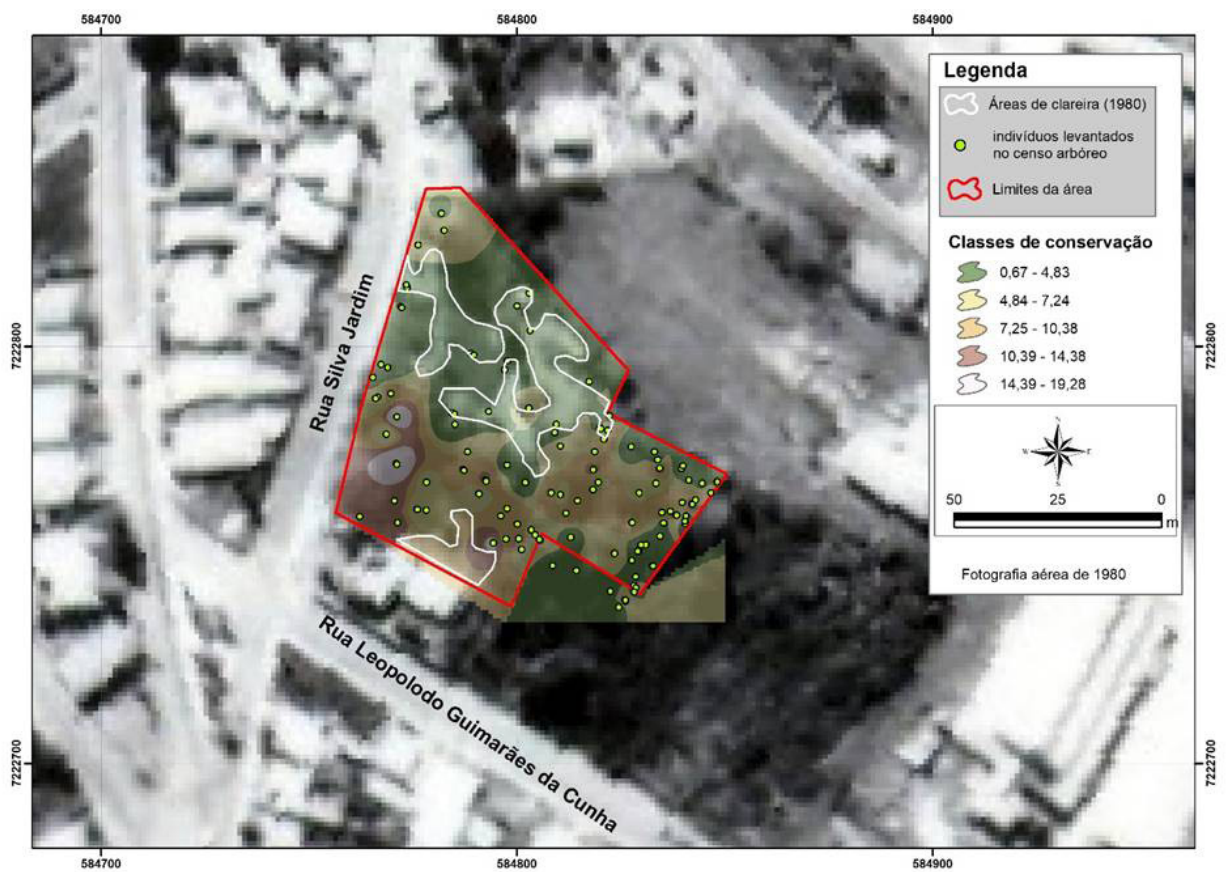

Fonte: os autores. 
Figura 13: Sobreposição das Classes de Conservação determinadas com a tomada de dados atual sobre imagem de satélite de 2004 .

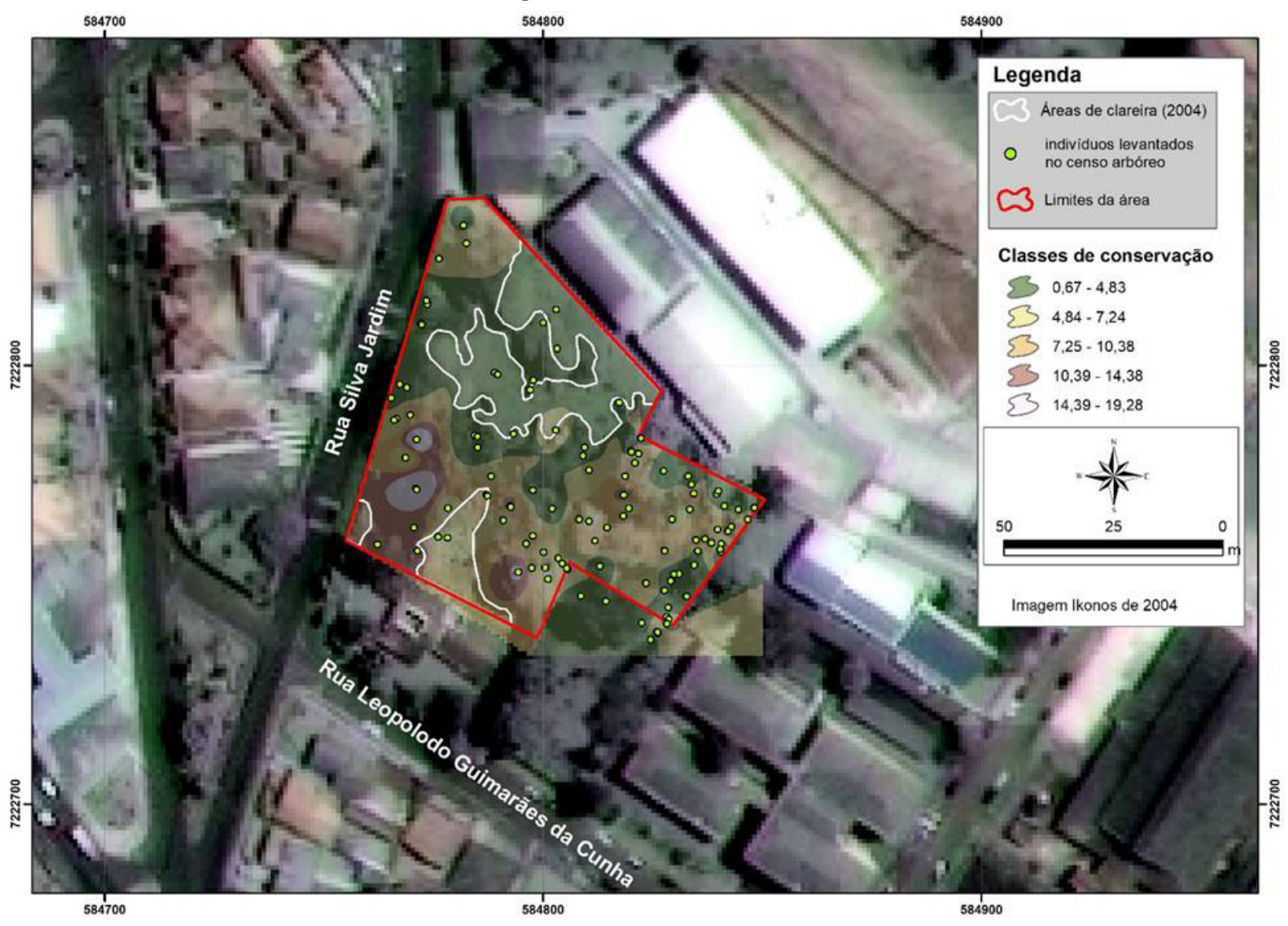

Fonte: os autores.

Outros atributos indicadores de relevância ecológica e/ou diferentes pesos entre os intervalos de índices utilizados neste estudo, podem ser atribuídos e adicionados à planilha de cálculo do I-VC como forma de contemplar aspectos particulares de uma área ou contexto local específico. Como exemplo, neste estudo não foi incorporado critério sobre a integridade dos elementos arbóreos no sentido de estimar longevidade e riscos de quebras de galhos ou de tombamento da própria árvore e seu efeito no índice de outros indivíduos. Esta análise pode ser definida a posteriori, entre os elementos que vão compor a área de conservação e paisagismo. Da mesma forma no processo de interpolação utilizado outros parâmetros relativos ao modelo estatístico podem ser modificados no sentido de valorizar indivíduos mais próximos ou ampliar a zona de influência de cada componente na determinação das zonas de manejo.

Finalmente, é importante abordar a perspectiva de transformar o local em área pública, através de desapropriação legal e adaptar o espaço para recreação e conservação. $\mathrm{O}$ custo elevado para desapropriar imóveis com remanescentes florestais restritos em sua composição florística e da superfície total protegida, deve ser levado em conta para direcionar eventual investimento público para aquisição de áreas mais relevantes em termos de superfície, composição arbórea e conectividade. 


\section{CONCLUSÕES}

Como referência de adequação do modelo, o resultado expresso em Zonas de Manejo foi compatível com a análise da distribuição e qualidade do remanescente florestal interpretado numa série temporal de cerca de 40 anos. Isto demonstra a viabilidade do modelo como referência objetiva da importância relativa de cada árvore, de espécies e da associação destas em zonas com relevância distinta.

A tomada de dados por AER revelou-se congruente com o inventário florestal e pode constituir uma etapa preliminar à seleção dos indivíduos para re-amostragem, caso já se disponha de um inventário recente, ou para o desenho amostral em áreas não inventariadas.

Ao colocar em perspectiva atributos ecológicos relevantes e sua distribuição espacial no imóvel na forma de mapas e tabelas georreferenciadas, o modelo pode ser referência para tomada de decisão em diferentes momentos de análise do empreendimento imobiliário: a) no planejamento arquitetônico e de ocupação do espaço; b) no paisagismo como estratégia de conservação e compensação ambiental; c) no processo de licenciamento ambiental e definição de compensação ambiental; d) na construção de obras; e, quando necessário, e) no processo de análise judicial.

\section{REFERÊNCIAS}

ALCOCK, I.; WHITE, M.P.; WHEELER, B.W. et al. Longitudinal effects on mental health of moving to greener and less green urban areas. Environmental science \& technology, v.48, n. 2, p. 1247-1255, 2014.

ARQUIPONTA Engenharia e Arquitetura Ltda. Edifício Vogue Square Garden - Estudo de Impacto de Vizinhança. Ponta Grossa, 2016.

AVERY, T.E.; G.L. BERLIN, G.L. Fundamentals of Remote Sensing and Airphoto Interpretation. New York: MacMillan, 1993. p. 377- 404.

BARROSO, D.A. O verde como estratégia de valorização imobiliária: a formação de um projeto urbanístico em São Paulo. Cadernos Metrópole, São Paulo, n. 18, p. 157-172, 2007. Disponível em: https://revistas. pucsp.br/metropole/article/viewFile/8734/6481 Acesso em: 10 maio 2019.

BARTON, J.; PRETTY, J. What is the Best Dose of Nature and Green Exercise for Improving Mental Health? A Multi-StudyAnalysis. Environ. Sci. Technol., v.44, p. 3947-3955, 2010.

CAMPOS, R.B.F.; CASTRO J.M. Áreas verdes: Espaços urbanos negligenciados impactando a saúde. Saúde \& Ttransformação Social, v.8, n. 1, p 106-116, 2017.

CASTELLA, P.R.; BRITEZ, R.M. (Org.) A Floresta com Araucária no Paraná: conservação e diagnóstico dos remanescentes florestais. Brasília: MMA, 2004.

CHEN, J.; SHENGTIAN, Y.; LI, H. et al. Research on geographical environment unit division based on the method of natural breaks (Jenks). International Archives of the Photogrammetry, Remote Sensing and Spatial Information Sciences, XL-4 (W3), v. 47, 2013.

FILGUEIRAS, T.S.; BROCHADO, A.L.; NOGUEIRA, P.E.; GUALA II, G.F. Caminhamento - um método expedito para levantamentos florísticos qualitativos. Cadernos de Geociências, v.12 p. 39-43, 1994.

GAIO, A. Lei da Mata Atlântica Comentada. São Paulo: Almedina, 2014.

GRISE, M. M.; BIONDI, D.; ARAKI, H. Distribuição Espacial e Cobertura de Vegetação das Tipologias de Áreas Verdes de Curitiba, PR. Floresta e Ambiente, v. 23, n. 4, p. 498-510, 2016.https://dx.doi. org/10.1590/2179-8087.127715 
INOUE, M.T.; RODERJAN, C.V.; KUNIOSHI, Y.S. Projeto Madeira do Paraná. Curitiba: Fundação de Pesquisas Florestais do Paraná, 1984.

JENKS, G.F. Optimal data classification for choroplethmaps. Lawrence: University of Kansas, 1977. (Occasional Paper, 2).

LENGLER, C. Enfoques da criação de unidade de conservação da natureza em zona urbana e a tributação desta propriedade: Estudo de caso do morro do osso em Porto Alegre, RS. Boletim Geográfico do Rio Grande do Sul, n.30, p. 9-32, 2017.

LOBODA, C.R.; DE ANGELIS, B.L.D. Áreas Públicas Urbanas: conceito, uso e funções. Ambiência. Guarapuava, PR. Ambiencia, v.1 n.1, p. 125-139, jan./jun. 2005. Disponível em: https:// revistas.unicentro. br/index.php/ambiencia/article/view/157/185 Acesso em: 10 maio 2019.

LONDE P.R.; MENDES P.C. A influência das áreas verdes na qualidade de vida urbana. Hygeia, v. 10, n. 18, p. 264-72, 2014.

LORENZI, H. Árvores Brasileiras: Manual de Identificação e Cultivo de Plantas Arbóreas Nativas do Brasil. Nova Odessa: Instituto Plantarum, 1992. v.1.

. Árvores Brasileiras: Manual de Identificação e Cultivo de Plantas Arbóreas Nativas do Brasil. 4.ed. Nova Odessa: Instituto Plantarum, 2004. v.2.

MACIEL, M.N.M; WATZLAWICK, L. F.; SCHOENINGER, E.R.; YAMAJI, F.M. Classificação Ecológica das Espécies Arbóreas. Ciências Agrárias e Ambientais, Curitiba, v.1, n.2, p. 69-78, abr./ jun. 2003.

MARTINELLI, G.; MORAES, M.A. (orgs.) Livro vermelho da flora do Brasil. Rio de Janeiro: Andrea Jakobsson/Instituto de Pesquisas Jardim Botânico do Rio de Janeiro, 2013.

OLIVEIRA, R.C.; OLIVEIRA, J.C. "Viver verde" como um "viver com qualidade": a nova roupagem estratégica dos empreendimentos imobiliários, ante a lacuna existente entre a legislação e a urbanização, em Salvador - BA. Revista de Direito Urbanístico, v. 2, n. 1, p. 39-59, 2016.

RIBEIRO, N.B.; MARTINS, M.S.; JOHNSSON, R.M.F. Construção de banco de dados geográficos para avaliação da vulnerabilidade ecológica em bacias hidrográficas: a experiência da Bacia Lagos São João, RJ. Revista Interface, v. 11, p. 18-33, 2016.

ROBERTSON, D.; HULL, R.B. Beyond biology: toward a more public ecology for conservation. Conservation Biology, v. 15, n. 4, p. 970-979, 2001.

ROSARIO, R.P.G. Estágios sucessionais e o enquadramento jurídico das florestas montanas secundárias na Reserva Florestal do Morro Grande (Cotia, SP) e entorno. São Paulo, 2010. Dissertação (Mestrado em Botânica) - Insituto de Botânica, IB. Disponível em: http:/ /arquivos.ambiente.sp.gov.br/pgibt/2013/09/ Ricardo_Pedro_Guazzelli_Rosario_MS.pdf. Acesso em: 30 jul. 2019.

SANTOS, M.F.B.; CADEMARTORI, C.V. Estudo comparativo da avifauna em áreas verdes urbanas da região metropolitana de Porto Alegre, sul do Brasil. Biotemas, v.23, n. 1, p. 181- 195, 2010.

SAYRE, R. et al. Natureza em foco: Avaliação Ecológica Rápida. Arlington: The Nature Conservancy, 2000.

SELL, E.B.D. Lei da Mata Atlântica: uma reflexão acerca da proteção da vegetação nativa nas áreas urbanas e regiões metropolitanas. 2015. Especialização em Direito Ambiental. Portal Unisul. Disponível em: https:/ / riuni.unisul.br/handle/12345/3601 Acesso em: 10 maio 2019.

SIDOL. Sistema de Identificaçào Dendrológica Online - Floresta Ombrófila Mista. Disponível em: http:/ / www.florestaombrofilamista.com.br/ Acesso em: 22 jul. 2019.

TAKANO, T; NAKAMURA, K.; WATANABE, M. Urban residential environments and senior citizens' longevity in megacity areas: the importance of walkable green spaces. J. Epidemiol. Community Health, v.56, p 913-918, 2002.

Data de submissão: 25/ ago./ 2019

Data de aceite: 30/ ago./ 2019 